\title{
Visual Inspection of Cervix with Acetic Acid as a Screening Test for Premalignant and Malignant Lesions of Cervix
}

\author{
${ }^{1}$ Shelly Agarwal, ${ }^{2}$ Samta Gupta, ${ }^{3}$ Nimmi Chutani, ${ }^{4}$ SS Gulati
}

\section{ABSTRACT}

Aims and objectives: To compare the efficacy of VIA and Pap smear for detection of premalignant and malignant lesions of cervix.

Materials and methods: Two hundred and forty women attending outpatient department of obstetrics and gynecology were subjected to detailed history taking, clinical examination, Pap smear and VIA, and biopsies were indicated.

Results: Of 240 patients, 27 patients (11.3\%) were Pap positive and 28 patients (11.7\%) were VIA positive. A total of 39 patients in whom either test was positive, had undergone cervical biopsy. Sensitivity of VIA and Pap smear was 92 and $84 \%$ respectively and specificity of VIA and Pap smear was 64.3 and $57 \%$ respectively.

Conclusion: The study concluded that sensitivity of VIA is comparable to Pap. Therefore, VIA is an efficacious and costeffective method to screen premalignant and malignant lesions of cervix, especially in developing countries like ours.

Keywords: Pap smear, VIA, Cervical biopsy.

How to cite this article: Agarwal S, Gupta S, Chutani N, Gulati SS. Visual Inspection of Cervix with Acetic Acid as a Screening Test for Premalignant and Malignant Lesions of Cervix. J South Asian Feder Menopause Soc 2014;2(2):62-64.

\section{Source of support: Nil}

Conflict of interest: None

\section{INTRODUCTION}

Cervical cancer is not only the commonest malignancy found among Indian women but also a leading cause of increasing morbidity and mortality of women. So, there is a need to have appropriate screening tests for early identification of premalignant and malignant lesions of cervix.

More so, cancer cervix has been considered preventable because of anatomical accessibility of cervix to direct examination and a long preclinical stage during which

${ }^{1}$ Assistant Professor, ${ }^{2}$ Associate Professor, ${ }^{3}$ Professor and Head, ${ }^{4}$ Professor

${ }^{1-4}$ Department of Obstetrics and Gynecology, School of Medical Sciences and Research, Greater Noida, Uttar Pradesh, India

CorrespondingAuthor: ShellyAgarwal,AssistantProfessor, Department of Obstetrics and Gynecology, School of Medical Sciences and Research,Greater Noida, India, e-mail: drshellyagarwal@yahoo.com precursor lesions can be treated conservatively and successfully. This makes cervical neoplasia ideal for secondary preventive efforts (i.e., the screening methods).

With the advent of Pap smear as a screening methods, the incidence of cancer cervix has fallen down by 50 to $75 \%$ in the developed countries but on contrary Pap smear in developing countries has not been much effective. The reason for the same being, the need of multiple visits. At least three visits are mandatory (1) 1st visit to perform the test, (2) 2nd visit to obtain the result, (3) 3rd visit for treatment. This leads to loss of follow-up of women, who are at greatest risk of cervical cancer.

So, the key success of cervical cancer screening program would be the one which ensures broad coverage of services. VIA is one such method which provides women with immediate tests and results. It also eliminates the need of laboratory and transport of specimens and does do not require much of equipments.

\section{MATERIALS AND METHODS}

Study was carried out in the Department of Obstetrics and Gynecology, Sharda Hospital, Greater Noida. A total of 240 women attending the gynecology outpatient department were enrolled in the study.

Patients between 30 and 55 years of age with complaints of vaginal discharge, irregular bleeding per vaginum, intermenstrual bleeding, postcoital bleeding and on examination showed unhealthy cervices, were all included in our study.

\section{EXCLUSION CRITERIA}

- Pregnant women

- Women not sexually active

- Frank growth on cervix

- Actively bleeding female

An informed consent was taken from all women included in our study. Detailed history of patient was taken, followed by per-speculum examination. Pap smear was then taken using ayre's spatula and evaluated by Bethesda system. Then, VIA was performed using 3\% acetic acid and result evaluated after 1 minute of application. Distinct acetowhite areas in transformation zone were taken as 
VIA positive. If negative or doubtful, then the VIA was considered negative. Cervical biopsy was performed for all patients positive for either of the tests.

The results were then analyzed for sensitivity, specificity and positive and negative predictive value.

\section{RESULTS}

Table 1 shows that out of 240 patients enrolled in our study, 27 patients $(11.3 \%)$ had a positive PAP test. Of the remaining 213 patients, 110 patients $(45.8 \%)$ had normal Pap smear, 98 patients $(40.8 \%)$ had an inflammatory smear and five patients (2.1\%) were reported to have ASCUS. Patients with ASCUS were not reported Pap smear positive.

Table 2 shows that 28 patients (11.7\%) were VIA positive while remaining 212 patients $(88.3 \%)$ had normal VIA.

Table 3 shows that out of 27 patients Pap smear positive, 21 patients (i.e. $77.8 \%$ ) had LSIL, HSIL, CIS or cancer cervix on cervical biopsy, while 6 patients $(22.2 \%)$ tested Pap smear positive were negative on histopathological examination (cervical biopsy). Twelve patients (5\%) were tested negative on Pap smear, but positive on VIA. Of these 12 VIA positive patients, four patients were tested positive on histopathological examination (cervical biopsy).

Table 4 shows that out of 28 patients tested VIA positive, 23 patients $(82.1 \%)$ had LSIL and HSIL on cervical biopsy, while five patients (17.8\%) tested VIA positive, were negative on histopathological examination (cervical biopsy). Eleven patients (4.6\%) were tested negative on VIA, but positive on Pap smear. Of these 11 patients, two patients were positive on cervical biopsy.

Table 5 shows sensitivity, specificity, negative predictive value and positive predictive value of both screening tests.

Table 1: Results of pap smear

\begin{tabular}{ll}
\hline Pap smear report & Number of patients \\
\hline Normal & 110 \\
Inflammatory & 98 \\
ASCUS & 5 \\
LSIL & 19 \\
HSIL & 6 \\
CIS & 0 \\
Ca-cervix & 2 \\
\hline Total & 240 \\
\hline
\end{tabular}

Table 2: Results of VIA

\begin{tabular}{ll}
\hline Result of VIA & Number of patients \\
\hline Positive VIA & 28 \\
Negative VIA & 212 \\
\hline Total & 240 \\
\hline
\end{tabular}

Table 3: Correlation between pap smear and cervical biopsy

\begin{tabular}{llll}
\hline Pap smear & \multicolumn{2}{c}{$\begin{array}{c}\text { Cervical biopsy } \\
\text { findings }\end{array}$} & Total \\
\cline { 2 - 3 } & Positive & Negative & \\
\hline Positive & 21 & 6 & 27 \\
Negative & 4 & 8 & 12 \\
\hline Total & 25 & 14 & 39 \\
\hline
\end{tabular}

Table 4: Correlation between VIA and cervical biopsy

\begin{tabular}{llll}
\hline VIA & \multicolumn{2}{c}{ Cervical biopsy findings } & Total \\
\cline { 2 - 3 } & Positive & Negative & \\
\hline Positive & 23 & 5 & 28 \\
Negative & 2 & 9 & 11 \\
\hline Total & 25 & 14 & 39 \\
\hline
\end{tabular}

Table 5: Tests characteristics of screening tests in detecting premalignant and malignant lesions of cervix

\begin{tabular}{lll}
\hline & Pap smear (\%) & VIA (\%) \\
\hline Sensitivity & 84 & 92 \\
Specificity & 57 & 64.3 \\
Positive predictive value & 66.7 & 81.8 \\
Negative predictive value & 77.8 & 82.1 \\
\hline
\end{tabular}

\section{DISCUSSION}

In current study, women from all age groups were included. It revealed mean ages of LSIL and HSIL as 31.2 and 36.6 years whereas that of invasive carcinoma was 41.6 years. This was comparable to large study performed by Luthra et al. ${ }^{1}$ So, screening for cervical carcinoma should start ideally at the onset of sexual activity and screened regularly after 30 years.

In multicentric study done by Sankaranarayanan et $\mathrm{al}^{2}$ in 2004, sensitivity of VIA ranged from 56.10 to $93.90 \%$ and specificity ranged between 74.20 and $93.80 \%$. In another study performed by Cronje et al, ${ }^{3}$ sensitivity and specificity of Pap smear were 53 and $95 \%$ while that of VIA were 79 and $49 \%$ respectively. In meta-analysis performed by Fahey et al ${ }^{4}$ in 1995, mean sensitivity and specificity of cytology was 58 and $68 \%$ respectively.

Considering various studies, results of sensitivity and specificity of Pap smear and VIA in our study were comparable. In our study, sensitivity and specificity of Pap smear was 84 and 57\% respectively and that of VIA was 92 and 64.3\% respectively. High sensitivity of VIA, makes it a useful screening procedure specially in low resource settings. From our data, VIA has a comparable sensitivity and specificity with Pap smear. However, reasons of high sensitivity and low specificity of VIA in our study could be due to presence of infection that take acetowhite stains. 
Many studies have been carried out to compare the sensitivity and specificity of VIA with Pap smear with varying result. ${ }^{5-9}$ One of the major reasons for wide variation in results of VIA is that it is observer dependent. It is thus necessary that standard training should be given to all healthcare providers before we use it as part of a national screening program to maintain quality control.

\section{CONCLUSION}

Mass screening with Pap smear has reduced the incidence of cervical cancer in developed countries. However, in developing countries like India, cervical cancer is still the leading cause of death from cancer, there is lack of an effective screening program. VIA has come as a boon in developing countries which is not only as sensitive as Pap smear but also is a cheap and easily available method, which does not require trained personnel and can be easily perfomed by paramedical workers.

Thus, VIA presents to us a good screening option with high sensitivity and reasonable specificity either singly or as adjunct to Pap smear.

\section{REFERENCES}

1. LuthraUK, Prabhakar AK, Seth P, Agarwal SS, Murthy NS, Bhatnagar $\mathrm{P}$, et al. Natural history of precancerous and early cancerous lesions of the uterine cervix. Acta Cytol 1987 May-Jun;31(3):226-234.

2. Sankaranarayanan R, Shyamalakumary B, Wesley R, Sreederi Amma N, Parkin DM, Nair MK: acetic acid in the early detection of cervical cancer and precursors. Int J Cancer 1999; 80(1):161-163.

3. Cronje H, Parham G, Cooreman B, de Beer A, Divall P, Bam R. A comparison of four screening methods for cervical neoplasia in developing country. Am J Obstet Gynaecol 2003 Feb;183(2):395-400.

4. Fahey MT, Irwig L, Macaskill P. Meta-analysis of Pap test accuracy. American Epidemiol 1995;141(7):680-689.

5. Denny L, Kuhn L, Pollack A, Wright TC Jr. Direct visual inspection for cervical cancer screening: an analysis of factors influencing test performance. Cancer 2002 Mar 15;94(6):1699-1707.

6. Akinwuntan AL, Adesina OA, Okolo CA, Adewole IF, Oladokun A, Ifemeje AA. Correlation of cervical cytology and visual inspection with acetic acid in HIV-positive women. J Obstet Gynaecol 2008;28(6):638-641.

7. Harshad S, Khunying K, Marya P, Elaine C, Amy K, Enriquito L, Wachara E, Buncha P. Cervical cancer screening using visual inspection with acetic acid: operational experiences from Ghana and Thailand. Reprod Health Mat 2008;16(32):67-77.

8. Akinola OI, Fabanwo AO, Oshodi YA, Banjo AA, Odusanya O, Gbadegesin A, Tayo A. Efficacy of visual inspection of the cervix using acetic acid in cervical cancer screening: a comparison with cervical cytology. J Obstet Gynaecol 2007;27(7):703-705.

9. World Health Organisation. Comprehensive cervical cancer Control: a guide to essential practice (Geneva: World Health Organization Publication) 2006. 